\title{
Microarchitecture of VLSI Computers
}




\section{NATO ASI Series}

\section{Advanced Science Institutes Series}

A Series presenting the results of activities sponsored by the NATO Science Committee, which aims at the dissemination of advanced scientific and technological knowledge, with a view to strengthening links between scientific communities.

The Series is published by an international board of publishers in conjunction with the NATO Scientific Affairs Division
A Life Sciences
Plenum Publishing Corporation
B Physics
London and New York
Mathematical and
Physical Sciences
D. Reidel Publishing Company
Dordrecht and Boston
D Behavioural and
Martinus Nijhoff Publishers
Social Sciences
Dordrecht/Boston/Lancaster
E Applied Sciences
F Computer and
Springer-Verlag
Systems Sciences
Berlin/Heidelberg/New York
G Ecological Sciences

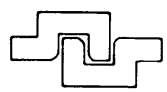

Series E: Applied Sciences - No. 96 


\section{Microarchitecture of VLSI Computers}

edited by

P. Antognetti

University of Genova

Genova, Italy

\section{F. Anceau}

INPG

Grenoble, France

\section{J. Vuillemin}

INRIA

Paris, France

1985 Martinus Nijhoff Publishers

Dordrecht / Boston / Lancaster

Published in cooperation with NATO Scientific Affairs Division 
Proceedings of the NATO Advanced Study Institute on Microarchitecture of VLSI Computers, Sogesta, Urbino, Italy, July 9-20, 1984

\section{Library of Congress Cataloging in Publication Data}

ISBN-13: 978-94-010-8775-9 e-ISBN-13: 978-94-009-5143-3

DOI: $10.1007 / 978-94-009-5143-3$

Distributors for the United States and Canada: Kluwer Boston, Inc., 190 Old Derby Street, Hingham, MA 02043, USA

Distributors for the UK and Ireland: Kluwer Academic Publishers, MTP Press Ltd, Falcon House, Queen Square, Lancaster LA1 1RN, UK

Distributors for all other countries: Kluwer Academic Publishers Group, Distribution Center, P.O. Box 322, 3300 AH Dordrecht, The Netherlands

All rights reserved. No part of this publication may be reproduced, stored in a retrieval system, or transmitted, in any form or by any means, mechanical, photocopying, recording, or otherwise, without the prior written permission of the publishers,

Martinus Nijhoff Publishers, P.O. Box 163, 3300 AD Dordrecht, The Netherlands

Copyright (c) 1985 by Martinus Nijhoff Publishers, Dordrecht

Softcover reprint of the hardcover 1st edition 1985 
PREFACE

We are about to enter a period of radical change in computer architecture. It is made necessary by advances in processing technology that will make it possible to build devices exceeding in performance and complexity anything conceived in the past. These advances, the logical extension of large - to very-large-scale integration (VLSI) are all but inevitable. With the large number of switching elements available in a single chip as promised by VLSI technology, the question that arises naturally is:

What can we do with this technology and how can we best utilize it? The final answer, whatever it may be, will be based on architectural concepts that probably will depart, in several cases, from past and present practices. Furthermore, as we continue to build increasingly powerful microprocessors permitted by VLSI process advances, the method of efficiently interconnecting them will become more and more important. In fact one serious drowback of VLSI technology is the limited number of pins on each chip. While VLSI chips provide an exponentially growing number of gates, the number of pins they provide remains almost constant. As a result comminication becomes a very difficult design problem in the interconnection of VLSI chips. Due to the insufficient commnication power and the high design cost of VLSI chips, computer systems employing VLSI technology will thus need to employ many architectural concepts that depart sharply from past and present practices.

This book focuses on the intermal microarchitecture of present and future microprocessors and microcomputers in VLSI technology. The authors of the different chapters represent a well balanced blend of academic and industrial backgrounds. The academic authors describe more general, research-oriented topics, while the authors coming from industry describe in detail the architecture of their latest products. In this way the readers have a unique opportunity to obtain a full description of the present (industrial) and future (academic) architectural concepts for VLSI computers.

The content of this book results from the lecture notes handed out at the NATO ASI, held at SOGESTA, Urbino, Italy, from JuZu 9 to 
July 20, 1984.

I would like to thank Drs. M. di LuZlo and C. Sinclair of NATO's Scientific Affairs Division for their helpful assistance in organizing the ASI, and the lecturers for their timely and accurate presentations and for their careful preparation of the text.

P. Antognetti

Director of the NATO-ASI

University of Genova, Italy

January, 1985. 
TABLE OF CONTENTS

PREFACE

PART I: VLSI ARCHITECTURES FOR MICROPROCESSORS

1. R.W. Hadse ZI

Micro/370

2. J.G. Fiasconaro

Microarchitecture of the HP9000 Series 500 CPU 55

3. E.M. MeCreight

The Dragon Computer System: An Early Overview

4. W. Sherwood

The VLSI VAX Chip Set Microarchitecture

5. A. De GLoria

External and Internal Architecture of the P32, a 32 Bit Microprocessor

6. W-D. Moeller and G. Sandweg

A Highly Regular Peripheral Processor

PART II: VLSI ARCHITECTURES FOR IMAGE PROCESSING

7. R.M. Lea

Scape: A VLSI Chip Architecture for Image Processing

8. G.D. Abram and H. Fuchs

VLSI Architectures for Computer Graphics

PART III: VLSI ARCHITECTURES FOR SYSTOLIC ARRAYS

9. A.I. Fisher, H.T. Kung and K. Sarocky Experience with the CMU Programmable Systolic Chip 
VIII

PART IV: TESTING OF VLSI CHIPS

10. P. Marchal, M. Nicolaidis and B. Courtois Microarchitecture of the MC 68000 and Evaluation of a Self Checking Version

SUBJECT INDEX 